\title{
Fábula e Mito na Literatura Tradicional Portuguesa - Pequenas Totalidades
}

Fable and Myth in Traditional Portuguese Literature - Small Totalities'

\author{
ANA PAIVA MORAIS \\ Universidade Nova de Lisboa \\ Portugal \\ anapm@fcsh.unl.pt
}

Resumo. Neste artigo pretende-se analisar modalidades do recurso ao mito na fábula esópica no sentido de fazer uma revisão do estatuto da fábula no sistema dos géneros da literatura tradicional. $\mathrm{Na}$ primeira parte, analisam-se perspectivas várias sobre a fábula, que vão desde concepções medievais à colecção de Manuel Mendes da Vidigueira, produzida no início de seiscentos, e à viragem da fábula da filosofia para a poética nas épocas posteriores a La Fontaine, culminando com a apropriação da fábula na colecção de contos tradicionais de Teófilo Braga. Na segunda parte, propõe-se uma leitura comparada da fábula «Juno e o pavão», que dá especial atenção à incorporação das fábulas de Manuel Mendes da Vidigueira na colecção de Teófilo Braga, argumentando que a fábula na literatura tradicional tende a desaparecer como género e a absorver as características do conto.

Palavras chave: Fábula; Mito; Literatura Tradicional; Forma e Género Literário; Conto.
Abstract. This article aims to study the inclusion of myth in Aesop's Fables in order to re-evaluate the role of fable in the genre system of traditional literature. In the first part, we analyse several perspectives on the fable, ranging from the Middle Ages and Manuel Mendes da Vidigueira's early seventeenth century collection, to the turn from the philosophical to the poetical fable in the aftermath of La Fontaine's Fables, and the selection of fables in Teófilo Braga's collection of traditional tales. The second part is a comparative study of the fable "June and the Peacock", focusing mainly on the uses of mythological material incorporated in Manuel Mendes da Vidigueira's fables in Braga's collection. Our observations about the function of myth in fables leads us to argue that the fable in traditional literature tends to loose its characteristics as an autonomous genre and to be absorbed by the tale.

Key words: Fable; Mythology; Traditional Literature; Literary Forms and Genres; Tales.

\footnotetext{
${ }^{\text {I }}$ Para citar este artículo: Morais, A.P. Fábula e Mito na Literatura Tradicional Portuguesa - Pequenas Totalidades. Alabe 5 , junio 2012 [http://www.ual.es/alabe]
} 


\section{Totalidades da fábula - resumir ao essencial}

Num estudo intitulado "Sobre a essência da fábula", Lessing distingue a fábula de outras modalidades da narrativa sentencial, afirmando que ela exige que haja diferentes imagens que concorrem para uma mesma finalidade, ou seja, que a fábula exige uma acção. O filósofo alemão especifica, ainda, que, no seu entendimento, a acção consiste numa sucessão de modificações que formam, em conjunto, um único todo: «a unidade de um todo consiste na harmonia de todas as partes tendendo para uma mesma finalidade» (Lessing, 2008). A ideia de que a fábula forma uma pequena totalidade é central em Lessing, mas é necessário ir um pouco mais além para precisar o que ele entende por totalidade: a totalidade é aquilo que tende para uma finalidade única, e expressa-se na sentença moral. Mais tarde, um estudioso da fábula tão marcante como Ben Edwin Perry afirmava, sendo nisto secundado por vários outros teóricos, que o objectivo moral é a qualidade essencial que distingue a fábula de outros contos de animais, e dizia que esse objectivo deve ser único e não admitir ambiguidade (Perry, I959).

As fábulas figuram em várias colecções de narrativas tradicionais constituídas no final do século XIX e já no século XX. Tanto Teófilo Braga como Leite de Vasconcelos assinalam, este último mais modestamente, a existência de textos que classificam como fábulas nos seus corpora de contos populares. No entanto, estas fábulas têm a singularidade de não apresentarem moral. Na edição de I9I4-I9I5 dos Contos Tradicionais do Povo Português (Braga, I9I5) ao introduzir as fábulas da obra de Manuel Mendes da Vidigueira (Mendes [da Vidigueira],I6o3), Teófilo tem o cuidado de as apresentar sem os epimítios moralizados, de modo a mostrar como, segundo ele, estes textos faziam originalmente parte de um fundo universal de onde emanava a sabedoria popular. As seis fábulas que figuram na sua colecção à margem das fábulas de Manuel Mendes também se apresentam depuradas de uma moralidade final. A relação com o mito é assegurada, para Teófilo, justamente por uma depuração da fábula, e esta é conseguida através de uma libertação relativamente aos constrangimentos da moral que a desfigurava. Segundo Braga, a moral era problemática na fábula, em primeiro lugar, porque restringia o seu contexto de aplicação e o seu universo de referência, mas também, e sobretudo, porque introduzia um elemento de interferência, que era a razão, um factor perturbador da pureza e espontaneidade originais da expressão popular.

O breve estudo que aqui apresento parte destas duas teorias da universalidade da fábula para uma reflexão sobre a função (ou funções) do mito na fábula na literatura tradicional portuguesa, a qual será exemplificada, na sua segunda parte, por uma leitura comparada da fábula «Juno e o pavão».

Voltemos a Lessing. Na teoria da fábula apresentada pelo filósofo alemão pode facilmente notar-se uma inspiração aristotélica, sobretudo pela insistência na unidade narrativa da fábula como elemento constitutivo do género: 
outras não é o suficiente para formar uma fábula. E se a suposta acção de uma fábula pode ser apresentada integralmente através de uma imagem, isso é, a meu ver, uma prova infalível de que se trata de uma fábula deficiente que tão-pouco merece ser designada como fábula. Neste caso, ela apenas contém a imagem, e o pintor não nos ofereceu uma fábula, mas sim um emblema. [...] Ela não tem acção, apenas inclui um facto isolado e individual que cabe integralmente numa imagem. ${ }^{2}$ (Lessing, 2008: 42-43) $^{2}$

O principal problema que Lessing irá detectar no desenvolvimento da fábula a partir de La Fontaine reside na separação entre a fábula filosófica e a fábula poética. Segundo ele, a preocupação que o fabulista francês tem de ornamentar as fábulas de Fedro com uma nova alegria - «il fallait en recompense égayer l'ouvrage plus qu'il n’a fait / era necessário, em contrapartida, alegrar a obra mais do que ele fez» (I99I: 24-26) - residia, conforme confessa o próprio La Fontaine, na sua incapacidade para superar os mestres da fábula como Fedro e para oferecer ao leitor uma beleza de ordem mais essencial. Nesta falha em alcançar o fundo filosófico da fábula reside, segundo Lessing, o declínio deste género após La Fontaine, falha esta que teria decorrido, ainda na opinião do filósofo, de um erro de leitura do gramático latino Quintiliano e das teorias por este propagadas acerca da narrativa. Para os autores da Antiguidade, a fábula pertence ao domínio da filosofia, ao qual La Fontaine a arrancou para a inserir no universo poético, o que Lessing considera ser o ponto central de um desvio do género relativamente à sua vocação fundamental, que consistia em apontar verdades universais.

A aceitarmos a argumentação de Lessing, a era da fábula poética inicia-se, pois, com La Fontaine, em i668. Este momento marca o início de várias cisões relacionadas com a separação da fábula e do seu fundo filosófico inicial, que determinaram, por exemplo, o isolamento da fábula em universos especializados, como sejam a literatura infantil, ou o público feminino, perdendo a sua universalidade em consequência desta deriva. Ornamentar a fábula com uma linguagem poética foi a principal causa, afirma Lessing, do afastamento daquela relativamente à sua essência, ou seja, à vocação para a propagação de uma verdade essencial, para a qual tanto a brevidade como a concisão são imprescindíveis. Para La Fontaine, por outro lado, a única novidade que pode ter um género composto de narrativas que todos conhecem está no trabalho da linguagem, num apuramento poético, isto é, na escrita, e isto afasta La Fontaine, irremediavelmente, das preocupações de ordem universal, que dominam as reflexões de Lessing sobre a fábula.

Teófilo Braga, por outro lado, considera que a universalidade da fábula é um dado imprescindível ao seu funcionamento, mas, já muito longe das bases do pensamento de Lessing, para o crítico português, ela depende de uma relação fundamental com o mito. A ideia que Braga fornece da universalidade da fábula depende mais da transformação

\footnotetext{
${ }^{2}$ Tradução minha a partir da edição francesa. Note-se que, mais adiante, Lessing irá especificar o que entende por lei da unidade da fábula, demarcando-se da tese de Batteux que a generaliza, afirmando que este confundiu a acção da fábula com a da epopeia e do drama: «no caso destes dois últimos géneros, a acção deve ter, além do desfecho que o poeta projecta, um desfecho intrínseco e que propriamente lhe pertence. A acção da fábula não necessita de um tal desfecho intrínseco: ela é suficientemente perfeita quando o poeta, graças a ela, alcança o seu objectivo.» (Lessing, 2008: 5I).
} 
desta em algo que corresponde à sua ideia de conto tradicional, e, especificamente, depende da sua acomodação à estrutura do conto animal, do que da propagação da tradição moralizadora da fábula. Na verdade, a fábula é contada por si mesma, sendo a narrativa valorizada sobre o objectivo moral, que é obliterado. Esta redução da fábula ao sistema narrativo depende, no caso das fábulas de Teófilo, em grande parte de uma valorização dos protagonistas, quase sempre animais, em detrimento dos esquemas característicos da fábula, onde os protagonistas são incluídos na medida das funções que desempenham. No modo como recupera a colecção de Manuel Mendes, para figurar nos seus Contos Tradicionais do Povo Portugués, Teófilo promove o despojamento da funcionalidade das personagens animais, com a consequente intensificação da sua densidade empírica e material. Assim, poder-se-á dizer que, apesar de nos serem oferecidos textos praticamente idênticos na colecção de Manuel Mendes e na secção "Fábulas de Esopo" dos Contos Tradicionais - que, aliás, menionam a autoria daquele fabulista de seiscentos - as fábulas de uma e de outra se distinguem profundamente na forma como nos diferentes contextos se constróem as figuras dos animais.

É necessário recordar, neste ponto, que as personagens animais dos contos de Teófilo Braga não se resumem às dos textos que vai buscar à colecção de Manuel Mendes; podemos contar na sua obra outras fábulas de fonte distinta 3 , e, ao lado destas, alguns contos de animais, que aparentemente se distinguem da fábula. Entre as fábulas incluídas na edição de I9I5, contam-se quatro retiradas do, então, recentemente descoberto Fabulário Português: são elas «a viúva e o alcaide» (34), «o judeu, o escudeiro e as perdizes» (45), «o leão e o pastor» (27) e «o lobo e o cordeiro» (2) (Vasconcelos, I9O3-I9O5), em cuja trasladação Braga procedeu, como para as demais, omitindo os epimítios moralizados.

No quadro que Teófilo traça da literatura dos contos populares na transmissão oral das tradições, sobressai o parentesco da fábula com o mito. Da complexa teorização que Braga desenvolve sobre a questão do mito na tradição dos contos populares, destacaremos alguns aspectos, que aqui interessam particularmente. Dentro das ciências especiais por ele definidas, surge a filomitia, correspondente a «um estado mental de credulidade em que ficaram os povos que não chegaram pela dúvida e cepticismo às noções racionais» (Braga, ı9I5: I6). Nesta incluem-se cosmogonias, teogonias, mitos siderais e solares, mitos telúricos e meteorológicos, mitos antropomórficos e antropopáticos, símbolos e emblemas, alegorias, fábulas e comparações, lendas, ritos, drama cultual e iconografia. A filosofia, por outro lado, corresponde à fase mais elaborada da racionalização, e afasta-se, assim, da expressão natural do pensamento popular. O mito, por seu turno, situa-se num estádio intermédio da evolução para o pensamento racional, apresentando os fenómenos

\footnotetext{
3 «A raposa e o galo» (a fonte citada é anónima, mas Teófilo refere a sua inclusão nos Contos Populares da GrâBretanha, trad. De Bruyere, e nas Fábulas de La Fontaine); «O rato da cidade e o rato da aldeia», «O leão enfermo», «O Bacorote, as ovelhas, o lobo e os porcos da aldeia» e «O cervo e o cavalo», Sá de Miranda; "A formiga e a cigarra», «O cão sôfrego», «A rã e o boi» de Diogo Bernardes, «As lebres e as rãs» D. Francisco Manuel de Melo, «O Conselho dos ratos», «A tartaruga e a águia» e «O homem, o ídolo e o tesouro», Frei João de Ceita. (Braga, I9I4-I9I5, II: $250-268)$.
} 
da natureza sob representações personificadas. Neste quadro, Teófilo situa a fábula num ponto inferior ao mito na escalada para a racionalização, e considera este género como a manifestação de um estádio original e puro da expressão popular:

Na morphologia dos Contos ha um desdobramento gradual que corresponde ao progresso mental; a Fabula, nascida de uma simples comparação material, eleva-se ao intuito moral no Apólogo, fixando-se na forma litteraria, e dissolvendo-se na corrente oral que apenas conserva a conclusão ou moralidade no Anexim. A fabula, depois da Metaphora, é a forma mais rudimentar do conto; nasce d'esse estado mental subjectivo, e d'esse sentimento religioso do animismo em que se dá falla ás cousas inanimadas como as pedras; esta faculdade subsiste ainda nos processos rhetoricos da prosopopea, e na imprecação espontânea do povo. (Braga, I883, I: XIX-XX)

\section{Juno e o pavão - análise comparativa}

Nas suas várias ocorrências em colecções medievais consultadas, a fábula «Juno e o pavão» transmite uma moral extremamente estável: ela trata, sem grandes alterações, um tema típico das fábulas, que na realidade é um tema duplo - a cobiça e a vaidade - e é ilustrada por uma sentença que, por várias vezes, se condensa num provérbio que figura no epimítio: «quem tudo quer tudo perde». A parte narrativa da fábula descreve as lamentações do pavão acerca das suas fracas capacidades vocais face ao rouxinol e relata a resposta de Juno, chamada a intervir, que lembra ao pavão que ele já obteve o seu quinhão de ventura ao ser dotado das mais belas penas do reino das aves, «cheias de olhos que se assemelham a estrelas» (Mendes [da Vidigueira], I79ı: 23). A fábula termina, em algumas das suas versões, com uma explanação, por parte de Juno, da repartição das virtudes pelas aves. Nalgumas versões, como a de Manuel Mendes da Vidigueira, a moral desenvolve esta fala de Juno, expondo argumentos acerca da metodologia utilizada por Deus na criação dos homens e especificando que ela consistiu, fundamentalmente, em repartir as qualidades por cada um.

Em primeiro lugar, observemos algumas das ocorrências desta fábula. Ela figura na colecção de Manuel Mendes, como já referi, e é retomada nos Contos Tradicionais do Povo Português (Braga, I9I5) ${ }^{4}$. No entanto, não figura nos Contos e Lendas Populares coligidos por Leite de Vasconcelos (Vasconcelos, I963) nem tão-pouco no Fabulário Portugués do século XV por ele editado em 1905. Bastará observarmos a fortuna desta fábula num reduzido conjunto de colecções medievais posteriores ao século XII para percebermos qual o princípio que rege esta disparidade das suas ocorrências nas colecções

\footnotetext{
${ }^{4}$ Apenas se considera o corpus desta fábula que diz directamente respeito à questão que aqui é tratada. Não incluímos, por isso, outras versões desta fábula incluídas em coleccões posteriores à de Manuel Mendes e anteriores aos Contos Tradicionais do Povo Portugués de Teófilo Braga, quase todas apresentadas como traduções, como sejam as de Manuel de Morais Soares (I785). Fabulas de Phedro, Miguel do Couto Guerreiro (I788). Fábulas de Esopo, Francisco Manoel do Nascimento [Filinto Elíseo] (I8I3). Fábulas escolhidas entre as de La Fontaine, e Curvo Semedo (1820). As melhores fábulas de La Fontaine.
} 
modernas. É fácil concluir que as colecções derivadas da adaptação anonymus neveletii perpetuam a ausência desta fábula, que já se verificava naquela colecção, enquanto nas que derivam do Novus Aesopus, por regra, ela se mantém. Assim, é possível observar a sua inclusão em outras colecções medievais, como as que circularam em língua vulgar francesa, que seguem esta fonte ${ }^{5}$, e, ainda, na primeira colecção produzida nesta língua vulgar, o Esope de Marie de France ${ }^{6}$, bem como na colecção de Lyon da autoria de Julien Macho (Ruelle, r982)?

No entanto, nada nesta repartição nos esclarece acerca da lógica da inclusão de uma figura mitológica. Na verdade, esta prática é bastante rara nas fábulas esópicas, e isso torna tanto mais intrigante este recurso nas poucas colecções em que ocorre.

Ao compararmos as várias ocorrências, é possível verificar que a divindade nem sempre coincide com Juno, sendo identificada com o Destino na colecção de Marie de France, do século XII. É curioso observar que o tema da vaidade é retomado nesta colecção numa outra fábula, "A lebre e o cervo», onde a lebre, lamentando a ausência de belas hastes como as do cervo, pede a intervenção de uma divindade ${ }^{8}$.

Uma comparação das várias versões da fábula «Juno e o pavão» e desta última, «A lebre e o cervo» - a qual não se inclui na colecção de Manuel Mendes nem, consequentemente, na de Teófilo Braga -, permite-nos verificar que a divindade aparece nas fábulas com dois tipos diversos de atitudes.

Na maioria dos casos, a impossibilidade de atender os desejos do pavão é compensada com um discurso explicitamente apresentado como uma consolação: se o pavão não pode ter a bela voz do rouxinol, ele é senhor, por outro lado, da beleza; e todos os animais têm de se conformar, tal como ele, com a repartição da fortuna. Esta atitude, de certa forma, antecipa a moral, onde se explicita a lição a tirar, e Juno aparece, assim, como uma entidade que antecipa a lição da moralidade e, de algum modo, participa na sua construção.

Na colecção de Marie de France, por outro lado, encontramos uma das poucas versões desta fábula onde a deusa se apresenta irada perante as reclamações do pavão. Mais perto do final desta colecção, a fábula «A lebre e o cervo» vai mais longe, e a lebre é castigada pela sua própria cupidez, pois, sendo-lhe concedida a satisfação do seu desejo, com os belos cornos do cervo ela deixa de se conseguir locomover. É interessante atentar na repetição da expressão com que a divindade, em um e outro caso, saúda as pretensões tanto do pavão como da lebre: «deixa-me em paz!». Esta expressão parece estabelecer um fio condutor que opera uma ligação entre as duas fábulas e constitui um jogo de reflexos

\footnotetext{
5 Isopet II de Paris, fábula 39 e Isopet de Chartres, fábula 38 (Bastin, I929).

${ }^{6}$ Fábula 3I, (Marie de France, I99I).

7 Fábula IV, Livro IV (Ruelle, I982). Recueil Général des Isopets III. Paris; Société des Anciens Textes Français. Esta colecção constitui uma tradução do importante e influente Aesopus de Steinhöwel, o qual constituiu a primeira colecção impressa de fábulas.

8 «Sepande», uma divindade criadora, aqui a criadora dos animais, que o editor da colecção refere ser uma correspondência medieval de Júpiter, inserida com o intuito de reduzir o carácter antigo do texto.
} 
entre as duas situações, como que a sinalizar, na colecção, o lugar da intervenção do mito. No entanto, tal insistência na ligação da fábula ao mito não se verifica na colecção de Manuel Mendes, nem nos Contos Tradicionais do Povo Português, de Teófilo. Outra distinção a fazer entre a fábula «Juno e o pavão» na colecção de Marie e nas restantes que são aqui objecto de análise refere-se ao papel que assume a deusa numa e noutras. Na colecção de Marie refere-se que a deusa do Destino é criadora das penas do pavão e da voz do rouxinol. Possivelmente por ser aqui detentora do poder de criação, a sua atitude perante as reclamações do pavão seja a de ira.

Em duas outras colecções medievais em francês - o Isopet II de Paris e o Isopet de Chartres -, a criação é atribuída à Natureza, e, nestes casos, Juno apresenta-se como deusa consoladora. Num quarto caso no âmbito do corpus medieval, a colecção de Julien Macho (Ruelle ed., I982: I34-I35), por outro lado, descreve-se uma situação ambígua em que a Natureza é referida na moralidade como a entidade criadora, embora na fala de Juno, esta aponte os deuses como responsáveis pela criação da voz do rouxinol e das penas do pavão. Neste contexto, a atitude consoladora de Juno roça o ridículo, uma vez que se volta contra a própria deusa enquanto participante na criação que o pavão contesta.

Nas principais colecções medievais em francês, à excepção da colecção de Marie de France, é a Natureza, e não a divindade, que é responsável pelos atributos das aves. É certo que a Natureza aparece como uma entidade provida de uma dimensão alegórica, o que a coloca perto do estatuto dos deuses, mas parece haver aqui, sobretudo, o intuito de demarcar o plano dos deuses do de outras entidades mais próximas do mundo dos homens. Neste sentido, podemos dizer que, ao delegar o poder criativo na Natureza, Juno está a menorizar o papel dos deuses, e, de certa forma, também o seu próprio. Não podemos deixar de assinalar, neste ponto, um certo pendor cómico da fábula quando recorre ao exagero ou ao absurdo para apresentar as suas personagens fora do contexto em que normalmente as entenderíamos. O que aqui importa referir, acima de tudo, é que esta redução do papel da divindade corresponde a uma distanciação relativamente ao universo mítico. Juno deixa de ser a deusa que detém o poder sobre o mundo inferior para passar a ter a simples função de preparar a moralidade que será exposta no final. A divindade é, assim, uma entidade que espelha o narrador da fábula, que faz eco do seu discurso, que está ao serviço do contexto moral em que se situa a fábula e ao qual obedece o programa da colecção.

Manuel Mendes por seu lado, descreve uma situação diferente: Juno não faz qualquer menção à identidade do criador; mas na moral, menciona-se expressamente a natureza, que é depois, no epimítio, redefinida como ‘Deus’, sendo este apresentado como o «criador da natureza». Assim, na moral remete-se a criação para uma entidade que contrasta com aquela que se supõe ser a entidade criadora no corpo da fábula, o que cria um fosso mais profundo ainda entre os dois universos em causa: o dos deuses mitológicos e o da moral cristã.

O editor de I79I das fábulas de Manuel Mendes introduz um prólogo onde discorre sobre o papel pedagógico e moralizador da fábula, frisando a obrigatoriedade da 
moral e atribuindo a origem da fábula à invenção da alegoria ${ }^{9}$. Ora, uma análise comparativa da fábula «Juno e o pavão» permite, justamente, apreciar as limitações da alegoria e verificar a plasticidade da fábula, que se adequa melhor ou pior a este modelo: se a moral procura cristalizar-se em torno de figuras que representam tipicamente qualidades particulares, por exemplo, a raposa encarna o logro ou a astúcia, o lobo a voracidade e a força prepotente, a lebre, a inteligência ou a cobiça, e assim por diante, o recurso a figuras da mitologia parece servir este desígnio de um modo ideal, já que permite representar as acções humanas de modo abstracto e ideal em torno de determinadas forças sobrenaturais. Mas, ao observarmos de perto o modo como as fábulas organizam o recurso da mitologia podemos observar que existe alguma autonomia da fábula relativamente ao elemento mitológico, e que este género utiliza este recurso de modos vários, até chegar, por vezes, a aproximar-se de um tratamento cómico. De facto, Juno pode não se demarcar nitidamente, em certos casos, das personagens animais que povoam a fábula, como nos casos em que entra em diálogo com o pavão num plano quase equivalente e se limita a oferecer um ombro amigo ou, quando a moral se mantém, faz antepidamente eco da mensagem do narrador. Nesse sentido, a figura da divindade contrasta mais com as entidades divinas do que com as habituais personagens da fábula; nos casos em que se verifica o desaparecimento do epimítio moralizado, e apesar de este facto aparentemente indicar um recrudescimento da importância do mito, ela deixa de representar uma força universal para se colocar quase totalmente ao serviço da lógica moral, por vezes, já tendo sido objecto de uma visível cristianização, como é o caso na colecção de Manuel Mendes. A referência ao mito situa-se, assim, nas fábulas moralizadas, entre a animalização de Juno e a sua adaptação a uma moral cristã.

Na tradição popular, tendo perdido a conclusão moral, a aproximação de Juno ao plano dos animais é intensificada, e a lógica da sua resposta é resumida a um mero bomsenso humanizado que já nada tem que ver com a questão da criação transcendente. É nesse sentido que podemos afirmar que a totalidade da acção que é narrada na fábula se tornou mais reduzida, se particularizou notoriamente, se resumiu a um universo humano fechado no seu espaço mais próximo e imediato, sem permitir que o sentido se forme por meio de ecos universais que tenham expressão na moral conclusiva.

Assim, a teorização de Lessing que assentava na universalidade da fábula através de uma moral, que é totalizadora na medida em que se apresenta como síntese de uma acção, não tem aplicação nas fábulas da tradição popular.

Mas, se Teófilo, por sua vez, procura impor uma depuração da fábula ${ }^{\mathrm{Io}}$ para melhor chegar à expressão original da universalidade, a qual consistiria na manifestação autêntica do povo, também aqui nos deparamos com um projecto fracassado, que mais não

\footnotetext{
9 Não iremos, aqui, desenvolver a complexa discussão sobre a função alegórica da fábula, mas apenas focar alguns aspectos dessa função e do jogo que no nosso exemplo se realiza com o princípio da significação alegórica. Para um conhecimento mais extenso desta discussão, veja-se Strubel,I988 e Boivin, 2006.

Io Opção esta que não chega a ser teoricamente explicitada por Teófilo nas suas opções de edição.
} 
faz do que alargar a humanidade a um leque mais vasto de entidades, entre as quais a própria divindade parece também incluir-se. Tendo a fábula tradicional prescindido do contexto moral, e não apenas de uma moralidade textual, que parece ser o critério por excelência capaz de garantir o seu estatuto de expressão narrativa de uma totalidade, e, por outro lado, tendo operado uma considerável autonomização das personagens e reduzido a sua funcionalidade e a sua carga tipológica, é legítimo interrogarmo-nos sobre se o género da fábula existe, verdadeiramente, na literatura tradicional, ou, melhor, se ele resiste ao sistema literário tradicional, e se não terá aí a fábula sido submetida a uma outra ordem genológica, que ditou a sua assimilação, mais profundda do que seria de supor, pelas regras do conto. 


\section{REFERÊNCIAS BIBLIOGRÁFICAS}

- Bastin, Julia (ed.) (r929). Recueil Général des Isopets I. Paris: Librairie Ancienne Honoré Champion.

- Boivin, M.-J. (2006). La Naissance de la fable en français. Paris: Honoré Champion. Essais sur le Moyen Age, 33.

- Braga, T. (1883). Contos Tradicionais do Povo Português, I-II. Porto: Livraria Universal de Magalhães e Moniz Editores.

(1915). Contos Tradicionais do Povo Português, II. Lisboa: J. A. Rodrigues \& Ca, Editores (ed. ampliada). [reed.: (I987) Lisboa: Publicações Dom Quixote. Colecção Portugal de Perto]

- La Fontaine, J. de ([I668] I99I). Fables. Paris: Folio/Gallimard.

- Lessing, G.E. (2008). Traités sur la fable. Paris: Librairie Philosophique J. Vrin. Essais d'art et de philosophie.

- Marie de France (199I). (Charles Brucker ed.). Fables. Louvain: Peeters.

- Mendes [da Vidigueira], M., (I603). Fabulas de Esopo, traduzidas da língua grega com applicações moraes a cada Fabula. Évora: Manuel de Lyra. [ed. ut.: (I79I) Lisboa: Typographia Rollandiana].

- Perry, B.E. (1959). Fable. Studium Generale, ı2.

- Ruelle, Pierre (ed.), (1982). Recueil Général des Isopets III. Paris: Société des Anciens Textes Français.

- Strubel, A. (1988). Exemple, fable, parabole: le récit bref figure au Moyen Age. Le Moyen Age 94, 341-36I.

- Vasconcelos, J. L. de (ed.) (I9O3-I9O5). Fabulário Português. Revista Lusitana 8, 99-I5I. [reed.: Adelino de Almeida Calado (ed.) (r994). Livro de Exopo. Coimbra: Separata do Boletim Bibliográfico da Universidade de Coimbra 42].

- Vasconcelos, J.L. de (col.) (Soromenho, P.C. e Soromenho, A.S. (coords.)) (I963-1966). Contos Populares e Lendas I-II. Coimbra: Acta Universitatis Conimbrigensis. 